\title{
Maternal Plasma and Amniotic Fluid Chemokines Screening in Fetal Down Syndrome
}

\author{
Piotr Laudanski, ${ }^{1}$ Monika Zbucka-Kretowska, ${ }^{2}$ Karol Charkiewicz, ${ }^{1}$ Slawomir Wolczynski, \\ Daniela Wojcik, ${ }^{1}$ and Radoslaw Charkiewicz ${ }^{3}$ \\ ${ }^{1}$ Department of Perinatology and Obstetrics, Medical University of Bialystok, Marii Sklodowskiej-Curie 24a, \\ Podlasie, 15-276 Bialystok, Poland \\ ${ }^{2}$ Department of Reproduction and Gynecological Endocrinology, Medical University of Bialystok, Marii Sklodowskiej-Curie 24a, \\ 15-276 Bialystok, Poland \\ ${ }^{3}$ Department of Clinical Molecular Biology, Medical University of Bialystok, Waszyngtona 12, 15-269 Bialystok, Poland
}

Correspondence should be addressed to Piotr Laudanski; plauda@umb.edu.pl

Received 12 July 2014; Accepted 23 October 2014; Published 16 November 2014

Academic Editor: Sandra Helena Penha Oliveira

Copyright () 2014 Piotr Laudanski et al. This is an open access article distributed under the Creative Commons Attribution License, which permits unrestricted use, distribution, and reproduction in any medium, provided the original work is properly cited.

Objective. Chemokines exert different inflammatory responses which can potentially be related to certain fetal chromosomal abnormalities. The aim of the study was to determine the concentration of selected chemokines in plasma and amniotic fluid of women with fetal Down syndrome. Method. Out of 171 amniocentesis, we had 7 patients with confirmed fetal Down syndrome (15th-18th weeks of gestation). For the purpose of our control, we chose 14 women without confirmed chromosomal aberration. To assess the concentration of chemokines in the blood plasma and amniotic fluid, we used a protein macroarray, which allows the simultaneous determination of 40 chemokines per sample. Results. We showed significant decrease in the concentration of 4 chemokines, HCC-4, IL-28A, IL-31, and MCP-2, and increase in the concentration of CXCL7 (NAP-2) in plasma of women with fetal Down syndrome. Furthermore, we showed decrease in concentration of 3 chemokines, ITAC, MCP-3, MIF, and increase in concentration of 4 chemokines, IP-10, MPIF-1, CXCL7, and 6Ckine, in amniotic fluid of women with fetal Down syndrome. Conclusion. On the basis of our findings, our hypothesis is that the chemokines may play role in the pathogenesis of Down syndrome. Defining their potential as biochemical markers of Down syndrome requires further investigation on larger group of patients.

\section{Introduction}

The incidence of Down syndrome in the United States is estimated to be $1 / 732$ live births [1]. This syndrome is a result of a chromosomal aberration characterized by extra chromosome 21 or a fragment thereof. In people, with this aneuploidy, there is a high risk of congenital heart defects, gastroesophageal reflux syndrome, sleep apnoea, thyroid disease, and many other diseases [2].

Currently, the diagnosis of Down syndrome is based on noninvasive (biochemical, genetic, and ultrasound) and invasive (amniocentesis and chorionic villous sampling) prenatal test. Diagnostic efficacy of invasive method in combination with genetic diagnostics is $99.8 \%$ and they rarely give false positive results. However, these methods carry a $1 \%$ risk of miscarriage or fetal damage. In contrast, noninvasive tests themselves are connected with $5-10 \%$ false positives, and thus all positive results should be confirmed by the invasive methods. Therefore, there is a need for new potential biomarkers of Down syndrome which will provide enough data for a small percentage of false positive results that will not have to be confirmed by any invasive method [3].

Emerging evidence suggests that reproductive events and successful pregnancy outcome are under the regulatory control of cytokines and other inflammation-mediated factors but their role in human normal and abnormal pregnancies is still largely undefined [4-13]. The status of selected cytokines in amniotic fluid from chromosomal abnormal pregnancies has already been described [14].

The current increased incidence of chromosome abnormal pregnancy loss could depend on the aneuploidy, that correlates with a disturbance of the release of some cytokines of 
placental perfusion and uterine contraction. The imbalanced levels of inflammatory cytokines in the cases of abortion, preterm labour, premature rupture of the membranes, and fetal inflammatory response syndrome, where infection is absent, could be interpreted as a consequence of genetic feature that results in fetus participating in the mechanism of its own distress, death, and expulsion [15].

Moreover, one of the more recent publications revealed that most of the differentially expressed genes in Down syndrome belong to angiogenesis, immune response and inflammation pathways. It was shown that infected progenitors with trisomy 21 have a more pronounced deficit of immune response genes, mainly chemokines, than infected euploid cells [16]. Therefore, measurement of the chemokines in pregnancies with fetal chromosomal abnormalities could lead to better understanding of the influence of Down syndrome on such pregnancy and possibly provide new biomarker(s) for non-invasive genetic testing.

\section{Material and Methods}

The study and control groups consisted of women who underwent routine amniocentesis between 15th-18th weeks of gestation at the Department of Reproduction and Gynecological Endocrinology of the Medical University of Bialystok, Poland, (recruitment between 09.2012 and 10.2013). We performed 171 amniocentesis throughout the recruitment period. We recruited only nonfebrile women without any chronic or acute disease and also excluded those taking any type of hormonal or anti-inflammatory treatment as well as those with vaginal and urinary tract symptoms that would suggest infection.

The study protocol was approved by the Local Ethical Committee of Medical University of Bialystok, Poland, and an informed consent was obtained from, each patient (No ethics committee approval: R-I-002/36/2014). Signed informed consent from all participants involved in the study was obtained.

We obtained $5 \mathrm{~mL}$ of amniotic fluid during routine amniocentesis. $10 \mathrm{~mL}$ of peripheral blood was collected for EDTA probes after amniocentesis from each patient. The blood was then centrifuged, plasma subsequently separated and frozen at $-80^{\circ} \mathrm{C}$ temperature. After analysis of the caryotyping results, for the purpose of this study, we chose 7 women with trisomy 21 fetuses and for the control group we selected 14 healthy patients with uncomplicated pregnancies, who delivered healthy newborns at term.

To assess the concentration of chemokines in the blood plasma and in the amniotic fluid we used a multiplex method, which allows the simultaneous determination of 40 chemokines per sample. Like a traditional sandwich-based ELISA, it uses a pair of specific chemokine antibodies for detection. A capture antibody is first bound to the glass surface. After incubation with the sample, the target chemokine is trapped on the solid surface. A second biotin-labeled detection antibody is then added, which can recognize a different isotope of the target chemokine. The chemokine-antibodybiotin complex is then visualized through the addition of the streptavidin-labeled Cy3 equivalent dye using a laser scanner (GenePix 4100A).
The sets (Quantibody Array Human Chemokine, RayBiotech Inc.) consist of the following chemokines: CC chemokine ligand 21 (6Ckine/CCL21), protein tyrosine kinase (Axl), betacellulin (BTC), chemokine (C-C Motif) ligand 28 (CCL28), cutaneous T-cell attracting chemokine (CTACK/ CCL27), chemokine (C-X-C motif) ligand 16 (CXCL16), epithelial neutrophil-activating protein 78 (ENA-78/CXCL5), eotaxin-3/CCL26, granulocyte chemotactic protein 2 (GCP$2 / \mathrm{CXC})$, growth-regulated protein $\alpha, \beta, \gamma(\mathrm{GRO} \alpha / \mathrm{CXCL} 1$, GRO $\beta / \mathrm{CXCL} 2$, and GRO $\gamma / \mathrm{CXCL} 3)$, hemofiltrate cc chemokine 1 (HCC-1/CCL14), hemofiltrate CC chemokine 4 (HCC-4/CCL16), interleukin 9 (IL-9), interleukin 17F (IL-17F), interleukin 18 binding protein (IL18$\mathrm{BPa}$ ), interleukin 28A (IL-28A), interleukin 29 (IL-29), interleukin 31 (IL-31), Interferon Inducible Protein 10 (IP-10/ CXCL10), Interferon-Inducible T-cell alpha chemoattractant (I-TAC/CXCL11), leukemia inhibitory factor (LIF), ligand for herpesvirus entry mediator (LIGHT/TNFSF14), lymphotactin/XCL1, monocyte chemoattractant protein 2 (MCP-2/ CCL8), monocyte chemoattractant protein 3 (MCP-3/CCL7), monocyte chemoattractant protein 4 (MCP-4/CCL13), macrophage-derived chemokine (MDC/CCL22), macrophage migration inhibitory factor (MIF), macrophage inflammatory protein-3-alfa (MIP-3 $\alpha$ /CCL20), macrophage inflammatory protein-3-beta (MIP-3 $\beta / C C L 19)$, myeloid progenitor inhibitory factor 1 (MPIF-1/CCL23), neutrophil-activating peptide 2 (NAP-2/CXCL7), macrophage stimulating protein alpha $(\mathrm{MSP} \alpha)$, Osteopontin (OPN), pulmonary and activation-regulated chemokine (PARC/CCL18), platelet factor 4 (PF4), stromal cell-derived factor-1 (SDF-1/CXCL12), thymus and activation regulated chemokine (TARC/CCL17), thymus-expressed chemokine (TECK/CCL25), and thymic stromal lymphopoietin (TSLP).

We also performed CRP (C reactive protein) determination. CRP in plasma was measured using immunoturbidimetric method with the Multigent CRP Vario assay (detectable range was $0.2-480 \mathrm{mg} / \mathrm{L}$ ) detected on the ARCHITECT ci4100.

Descriptive statistics including mean concentration and standard error of the mean concentration were calculated for selected chemokines, henceforth called features. In order to detect statistically significant differences between considered groups (Down syndrome group versus control group), either fitting an analysis of variance model [17] was conducted or nonparametric method (Wilcoxon rank-sum test [18]) was applied. The choice of an appropriate method was made upon fulfilling the normality and the homogeneity of variances assumptions and in case of violation of at least one condition nonparametric approach was employed.

The normality of features distribution was checked with the Shapiro-Wilk test [19] and the homogeneity of variances with Levene's test [20]. Features that have been found significant, that is, their distribution was statistically significantly different among experimental groups, were taken under further investigation to discover their prediction capability. Receiver operating characteristic (ROC) curves were determined for statistically significant results between the groups of Down syndrome and control. The ROC curve describes the relationship between sensitivity (fraction of true positives) 
TABLE 1: Clinical characteristics of the patients.

\begin{tabular}{lcc}
\hline & $\begin{array}{c}\text { Group I: Down } \\
\text { syndrome } \\
\text { pregnancies } \\
(n=7)\end{array}$ & $\begin{array}{c}\text { Group II: pregnancies } \\
\text { without Down } \\
\text { syndrome } \\
(n=14)\end{array}$ \\
\hline $\begin{array}{l}\text { Maternal age } \\
\text { (median } \pm \text { SD) }\end{array}$ & $37.14 \pm 9.335$ & $33.21 \pm 8.192$ \\
$\begin{array}{l}\text { Number of } \\
\text { pregnancies } \\
\text { (median } \pm \text { SD) }\end{array}$ & $1.143 \pm 0.899$ & $1.214 \pm 1.051$ \\
$\begin{array}{l}\text { Gestational age at } \\
\text { collecting of } \\
\text { samples in weeks } \\
\text { (median } \pm \text { SD) }\end{array}$ & $15.77 \pm 0.834$ & \\
\hline
\end{tabular}

SD: standard deviation.

and the value of 1 - specificity (fraction of true negatives). Optimal threshold values were determined with the Youden method [21], confidence intervals for sensitivity and specificity corresponding to a particular threshold were calculated with the use of the Wilson method [22], and a test verifying that area under curve (AUC) was significantly greater than 0.5 (random classification) with the DeLong method [23] that was performed; $P$ values and one-sided confidence intervals for AUC are reported. Calculations concerning ROC curves and corresponding tests were conducted with the functions provided by the pROC R package [24]. Confidence intervals for sensitivity and specificity were constructed with the use of the binom.confint function, part of the binom R package. All calculations were carried out in $\mathrm{R}$ software environment [25]. Significance level alpha equal to 0.05 was applied for all statistical tests.

\section{Results}

Clinical characteristics of the patients are presented in Table 1. The values of mean concentration and standard error of maternal plasma and amniotic fluid chemokines concentrations in each study group and values are presented, respectively, in Tables 2 and 3.

Patients with fetal Down syndrome had higher plasma concentration of 1 chemokine: CXCL7 (NAP-2) and lower plasma concentration of 4 chemokines, HCC-4, IL-28A, IL31, and MCP-2 (Table 2), when compared to patients with healthy fetus.

In our study, we also showed that in the amniotic fluid of women with fetal Down syndrome when compared to patients with healthy fetus there exists significant decrease in concentration of 3 chemokines, that is, ITAC, MCP-3, and MIF. On the other hand, in the same amniotic fluid of fetuses with Down syndrome, as compared with control, we observed a significant increase in the concentration of 4 chemokines: 6Ckine, IP-10, MPIF-1, and CXCL7 (Table 3).

We included all statistically significant chemokines in later ROC analyses, but we created ROC curves only for chemokines significant in plasma (which has potential for noninvasive diagnosis), which set the threshold values and allowed predicting the likelihood of Down syndrome with specific sensitivity and specificity (minimal sensitivity was set to 0.7 ).

The area under the ROC curve for HCC- 4 was 0.73 ; for IL$28 \mathrm{~A}$ it was 0.79 ; for IL-31, it was 0.79 ; for MCP-2, it was 0.83 ; and for CXCL7 (NAP-2), it was 0.79 (Figure 1). We believe that all field values are satisfactory and indicate the usefulness of these biochemical markers as tools to predict the risk of Down syndrome. We demonstrated a significantly higher risk of Down syndrome when the plasma concentration of HCC$4<1574,65 \mathrm{pg} / \mathrm{mL}$ (sens. 0.86 , sp. 0.71, $P$ value $=0.0412$ ), IL$28 \mathrm{~A}<397.33 \mathrm{pg} / \mathrm{mL}$ (sens. 1 , sp. $0.71, P$ value $=0.0016$ ), IL-31 $<443.6 \mathrm{pg} / \mathrm{mL}$ (sens. 0.71, sp. $0.85, P$ value $=0.0017$ ), MCP-2 $<30,27 \mathrm{pg} / \mathrm{mL}$ (sens. 1 , sp. $0.71, P$ value $=0.0001$ ), and CXCL7 $(\mathrm{NAP}-2)>171,56 \mathrm{pg} / \mathrm{mL}$ (sens. 0.86 , sp. $0.71, P$ value $=0.0015$ ) (Figure 2).

Diagnostic values of these chemokines in plasma and amniotic fluid are presented, respectively, in Tables 4 and 5 .

We did not find any statistically significant differences when we compared plasma concentration of CRP between study and control group using Wilcoxon rank-sum test.

\section{Comment}

It is difficult to compare results of our investigation to any other research, because of the small amount of articles about chemokines profiling in maternal blood and amniotic fluid in patients with chromosomal abnormalities. Nevertheless, it is possible to associate some information existing in the science literature with our study results. There are potential explanations for the role of differentially expressed chemokines in the pathophysiology of Down syndrome.

IL-28A is one of two isoforms of IL-28, otherwise known as IFN-lambda 2 [26]. Paulesu et al. found increased production of interferon during uncomplicated pregnancy by cells of unstimulated placenta, decidua, placenta trophoblast, and macrophages [27]. This suggests that IFN plays (however, not completely known) a role in the proper development of the fetus. We have found reduced levels of IL-28A (IFNlambda) in the plasma of women with fetal Down syndrome. Moreover, our study has shown decreased plasma level of HCC-4 and amniotic fluid level of I-TAC, MIF of which production is largely dependent on the interferon [28-30]. Therefore, the decline in plasma concentration of IL-28A (interferon lambda 2) could result in a decrease in the concentration of HCC-4.

In our previous study, we found significantly lower concentration of HCC-4 in serum term pregnancies as compared to preterm and in other previous studies the same chemokine was increased in preeclampsia and fetal growth restriction [31] as well as in proliferative endometrium as compared to atrophic [32]. We therefore believe that HCC-4 is highly pleiotropic molecule and does not only participate in the inflammatory process, but also affects other processes such as neoorganogenesis [33].

The reduced levels of I-TAC and MIF in amniotic fluid might be dependent on IFN $-\gamma /$ IFN $-\beta$ and IFN- $\gamma /$ IFN $-\tau$, respectively $[29,30,34]$. On the other hand, our study 
TABLE 2: Concentrations of chemokines in maternal plasma.

\begin{tabular}{|c|c|c|c|}
\hline & $\begin{array}{l}\text { Group I: Down syndrome } \\
\text { pregnancies } \\
n=7\end{array}$ & $\begin{array}{c}\text { Group II: pregnancies } \\
\text { without Down syndrome } \\
\qquad n=14\end{array}$ & \multirow{2}{*}{$\begin{array}{l}P \text { value } \\
\text { Group I- } \\
\text { Group II }\end{array}$} \\
\hline & \multicolumn{2}{|c|}{ Chemokines concentration $(\mathrm{pg} / \mathrm{mL})$ Mean \pm SEM } & \\
\hline 6Ckine & $14976.6 \pm 2072.06$ & $20710.7 \pm 4887.08$ & 0.9710 \\
\hline Axl & $1172.4 \pm 83$ & $1480.5 \pm 249.07$ & 0.9131 \\
\hline BTC & $10605.3 \pm 977.53$ & $13437 \pm 2241.25$ & 0.9131 \\
\hline CCL28 & $7630.3 \pm 220.64$ & $9056.4 \pm 1261.94$ & 0.9710 \\
\hline CTACK/CCL27 & $3830.2 \pm 305.44$ & $4685.3 \pm 714.14$ & 0.7990 \\
\hline CXCL16 & $6781.2 \pm 452.89$ & $7501.4 \pm 731.94$ & 0.5182 \\
\hline ENA-78/CXCL5 & $3257.3 \pm 193.33$ & $5164.2 \pm 1146.31$ & 0.9131 \\
\hline Eotaxin-3 & $2079.1 \pm 250.3$ & $2895.2 \pm 357.21$ & 0.2245 \\
\hline GCP-2 & $499.5 \pm 46.54$ & $695.8 \pm 106.2$ & 0.2221 \\
\hline GRO $\alpha, \beta, \gamma / \mathrm{CXCL} 1, \mathrm{CXCL} 2, \mathrm{CXCL} 3$ & $498.3 \pm 41.08$ & $483.7 \pm 39.24$ & 0.8186 \\
\hline HCC-1/CCL14 & $1438.4 \pm 160.58$ & $1610.5 \pm 114.67$ & 0.3956 \\
\hline HCC-4/CCL16 & $1401.8 \pm 172.58$ & $1783.4 \pm 93.38$ & $0.0462^{*}$ \\
\hline IL-9 & $82744.2 \pm 6237.34$ & $112569.1 \pm 23155.3$ & 0.7573 \\
\hline IL-17F & $1581.4 \pm 161.2$ & $4763 \pm 1302.6$ & 0.1490 \\
\hline IL-18 BPa & $6866.4 \pm 850.07$ & $8645.5 \pm 1553.04$ & 0.9710 \\
\hline IL-28A & $282.3 \pm 29.8$ & $728.7 \pm 159.33$ & $0.0319^{* *}$ \\
\hline IL-29 & $17435 \pm 1282.24$ & $20785.5 \pm 3212.95$ & 0.9710 \\
\hline IL-31 & $418.7 \pm 47.19$ & $1971.5 \pm 495.91$ & $0.0309^{* *}$ \\
\hline IP-10/CXCL10 & $694.7 \pm 38.72$ & $706.6 \pm 82.24$ & 0.3601 \\
\hline I-TAC/CXCL11 & $119.5 \pm 16.09$ & $261.1 \pm 67.8$ & 0.2245 \\
\hline LIF & $1588.3 \pm 117.81$ & $2350.8 \pm 432.73$ & 0.5846 \\
\hline LIGHT/TNFSF14 & $159.6 \pm 6.18$ & $281.4 \pm 56.17$ & 0.3601 \\
\hline Lymphotactin/XCL1 & $2345.9 \pm 135.17$ & $3093.7 \pm 467.96$ & 0.7433 \\
\hline MCP-2/CCL8 & $24.4 \pm 1.7$ & $38.7 \pm 5.08$ & $0.0125^{* *}$ \\
\hline MCP-3/CCL7 & $112.5 \pm 11.63$ & $172.2 \pm 34.83$ & 0.6888 \\
\hline MCP-4/CCL13 & $155.4 \pm 14.35$ & $232.26 \pm 36.49$ & 0.1647 \\
\hline MDC/CCL22 & $3408 \pm 330.74$ & $3036.5 \pm 283.09$ & 0.4342 \\
\hline MIF & $920.3 \pm 278.35$ & $945.5 \pm 127.95$ & 0.9254 \\
\hline MIP-3a (CCL20) & $12.1 \pm 1.08$ & $34.8 \pm 8.69$ & 0.0811 \\
\hline MIP-3b/CCL19 & $816.9 \pm 79.04$ & $1910.2 \pm 447.75$ & 0.0938 \\
\hline MPIF1/CCL23 & $2967.3 \pm 372.87$ & $2583 \pm 306.44$ & 0.2872 \\
\hline MSPa & $3475.8 \pm 702.62$ & $4182.9 \pm 626.75$ & 0.4965 \\
\hline NAP-2/CXCL7 & $195.3 \pm 13.96$ & $154.3 \pm 10.85$ & $0.0370^{*}$ \\
\hline OPN & $8999.1 \pm 3494.15$ & $10607.3 \pm 2222.93$ & 0.6359 \\
\hline PARC/CCL18 & $2429.1 \pm 216.55$ & $2552.5 \pm 322.64$ & 0.6359 \\
\hline PF4 & $15460.4 \pm 1005.84$ & $19633.4 \pm 2102.81$ & 0.1929 \\
\hline SDF-1/CXCL12 & $275.1 \pm 31.54$ & $462.6 \pm 104.53$ & 0.5846 \\
\hline TARC/CCL17 & $29.9 \pm 4.92$ & $85.2 \pm 32.58$ & 0.9671 \\
\hline TECK/CCL25 & $6428.8 \pm 585.25$ & $9590.1 \pm 2064.78$ & 0.8557 \\
\hline TSLP & $364.2 \pm 25.3$ & $1559.4 \pm 438.2$ & 0.0793 \\
\hline
\end{tabular}

${ }^{*}$ Statistically significant value of less than 0.05 for Student's $t$-test.

${ }^{* *}$ Statistically significant value of less than 0.05 for Mann-Whitney-Wilcoxon test. 
TABLE 3: Concentrations of chemokines in amniotic fluid.

\begin{tabular}{|c|c|c|c|}
\hline & $\begin{array}{l}\text { Group I: Down syndrome } \\
\text { pregnancies } \\
n=7\end{array}$ & $\begin{array}{l}\text { Group II: pregnancies } \\
\text { without Down syndrome } \\
\qquad n=14\end{array}$ & \multirow{2}{*}{$\begin{array}{l}P \text { value* } \\
\text { Group I- } \\
\text { Group II }\end{array}$} \\
\hline & \multicolumn{2}{|c|}{ Chemokines concentration $(\mathrm{pg} / \mathrm{mL})$ Mean \pm SEM } & \\
\hline 6Ckine & $15218.2 \pm 4443.88$ & $5247.1 \pm 1557.9$ & $0.0379^{* *}$ \\
\hline Axl & $362.3 \pm 221.5$ & $241.9 \pm 99.41$ & 0.1718 \\
\hline BTC & $2975.9 \pm 1845.71$ & $2713.4 \pm 1146.08$ & 0.7577 \\
\hline CCL28 & $509.2 \pm 155.93$ & $1615.4 \pm 521.36$ & 0.0675 \\
\hline CTACK/CCL27 & $501 \pm 65.36$ & $855.7 \pm 343.16$ & 0.6590 \\
\hline CXCL16 & $6974.2 \pm 1614.47$ & $6474.6 \pm 675.76$ & 0.6888 \\
\hline ENA-78/CXCL5 & $387.4 \pm 83.7$ & $1358.6 \pm 460.2$ & 0.6888 \\
\hline Eotaxin-3 & $2046 \pm 1486.33$ & $876.7 \pm 206.93$ & 0.9710 \\
\hline GCP-2 & $4039.6 \pm 1086.68$ & $5637.2 \pm 1204.97$ & 0.4064 \\
\hline GRO $\alpha, \beta, \gamma / \mathrm{CXCL} 1, \mathrm{CXCL} 2, \mathrm{CXCL} 3$ & $\begin{array}{c}\text { All values below the range } \\
\text { of quantification }\end{array}$ & $213.3 \pm 18.41$ & \\
\hline HCC-1/CCL14 & $830.4 \pm 32.73$ & $784.6 \pm 213.38$ & 0.3223 \\
\hline HCC-4/CCL16 & $356.2 \pm 178.6$ & $269.6 \pm 73.05$ & 0.7990 \\
\hline IL-9 & $189.7 \pm 1572.82$ & $658.6 \pm 15762.47$ & 0.0795 \\
\hline IL-17F & $658.7 \pm 51.63$ & $658.6 \pm 207.34$ & 0.5549 \\
\hline IL-18 BPa & $2336.6 \pm 2052.55$ & $3007.4 \pm 1109.63$ & 0.0823 \\
\hline IL-28A & $62.9 \pm 15.95$ & $255.6 \pm 74.43$ & 0.1061 \\
\hline IL-29 & $1711.3 \pm 417.42$ & $4609.3 \pm 1698.43$ & 0.4698 \\
\hline IL-31 & $2001 \pm 1490.36$ & $479.8 \pm 88.54$ & 0.8125 \\
\hline IP-10/CXCL10 & $1284 \pm 124.32$ & $623.3 \pm 130.48$ & $0.0056^{* *}$ \\
\hline I-TAC/CXCL11 & $30.9 \pm 9.21$ & $103 \pm 25.55$ & $0.0097^{* *}$ \\
\hline LIF & $707.7 \pm 155.96$ & $465.3 \pm 161.85$ & 0.1827 \\
\hline LIGHT/TNFSF14 & $45.6 \pm 14.77$ & $125.9 \pm 30.51$ & 0.0930 \\
\hline Lymphotactin/XCL1 & $483.8 \pm 172.81$ & $962.8 \pm 212.61$ & 0.2065 \\
\hline MCP-2/CCL8 & $8.6 \pm 172.81$ & $24.5 \pm 5.07$ & 0.0757 \\
\hline MCP-3/CCL7 & $16.6 \pm 3.3$ & $69.3 \pm 17.73$ & $0.0297^{* *}$ \\
\hline MCP-4/CCL13 & $572.7 \pm 154.87$ & $1197.1 \pm 328.18$ & 0.4940 \\
\hline MDC/CCL22 & $6979.1 \pm 1134.39$ & $8553.8 \pm 1654.87$ & 0.5357 \\
\hline MIF & $987.5 \pm 212.7$ & $3213.2 \pm 642.93$ & $0.0052^{* *}$ \\
\hline MIP-3a (CCL20) & $437.5 \pm 220.5$ & $705.8 \pm 384.72$ & 0.9131 \\
\hline MIP-3b/CCL19 & $55.2 \pm 58.95$ & $254.4 \pm 89.81$ & 0.7242 \\
\hline MPIF1/CCL23 & $1599.9 \pm 471.2$ & $684.8 \pm 191.85$ & $0.0379^{* *}$ \\
\hline $\mathrm{MSPa}$ & $494.4 \pm 116.29$ & $1109.3 \pm 242.83$ & 0.0556 \\
\hline NAP-2/CXCL7 & $571.2 \pm 40.21$ & $374.2 \pm 38.54$ & $0.0048^{*}$ \\
\hline OPN & $26831.4 \pm 2550.4$ & $38045.8 \pm 5993.53$ & 0.3223 \\
\hline PARC/CCL18 & $\begin{array}{l}\text { Most of values below of } \\
\text { range of quantification }\end{array}$ & $534.5 \pm 173.62$ & \\
\hline PF4 & $12437.2 \pm 2184.23$ & $23243.3 \pm 4852.86$ & 0.0556 \\
\hline SDF-1/CXCL12 & $1221.5 \pm 345.75$ & $1070.9 \pm 265.25$ & 0.5846 \\
\hline TARC/CCL17 & $6.5 \pm 0.32$ & $25.7 \pm 9$ & \\
\hline TECK/CCL25 & $4700.2 \pm 531.33$ & $3998.8 \pm 950.29$ & 0.1101 \\
\hline TSLP & $180.7 \pm 79.67$ & $250.9 \pm 74.86$ & 0.5600 \\
\hline
\end{tabular}

${ }^{*}$ Statistically significant value of less than 0.05 for Student's $t$-test.

** Statistically significant value of less than 0.05 for Mann-Whitney-Wilcoxon test. 

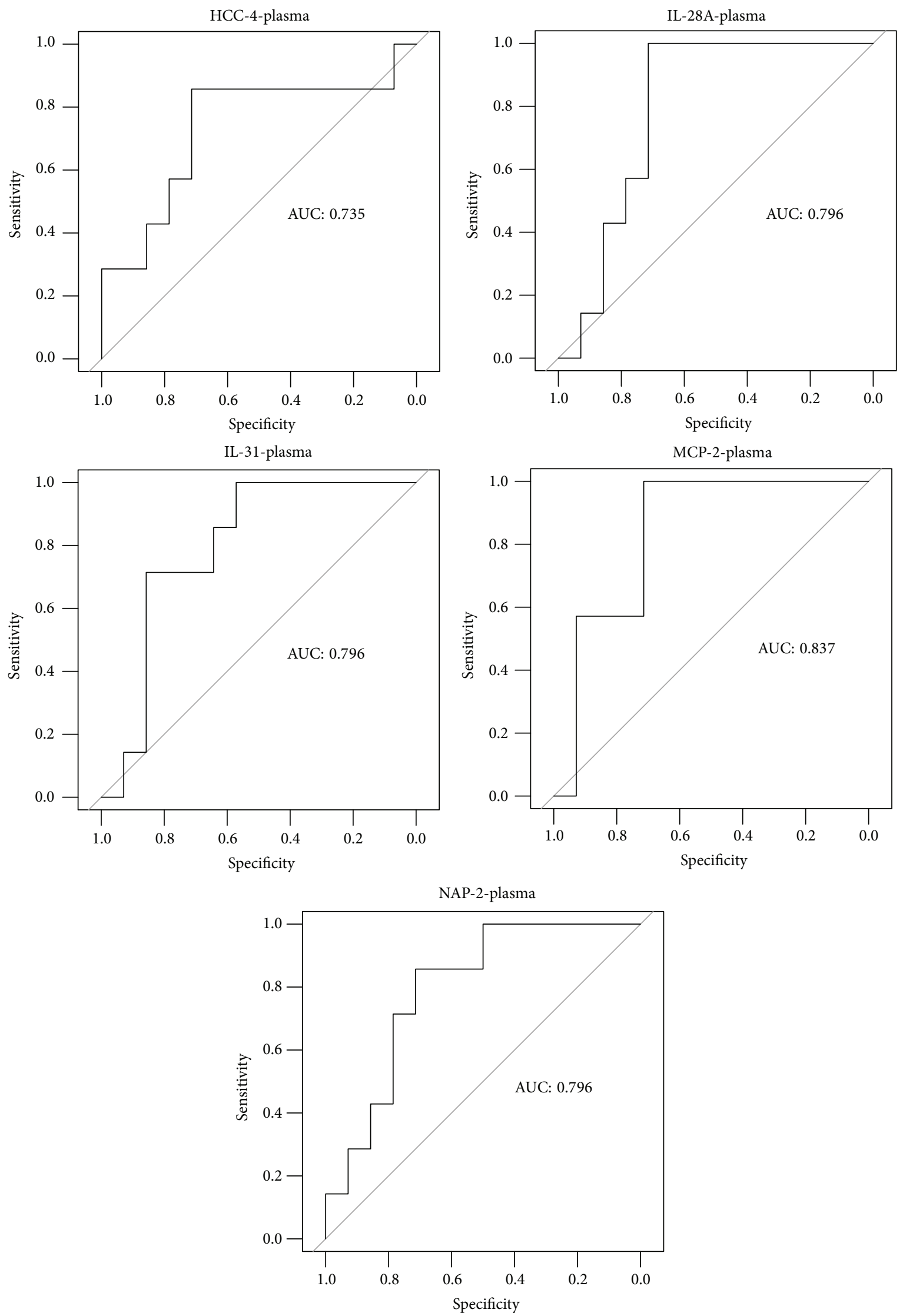

FIgURE 1: The ROC curves for concentration of chemokines in plasma: HCC-4, IL-28A, IL-31, MCP-2, and NAP-2 (CXCL7). 

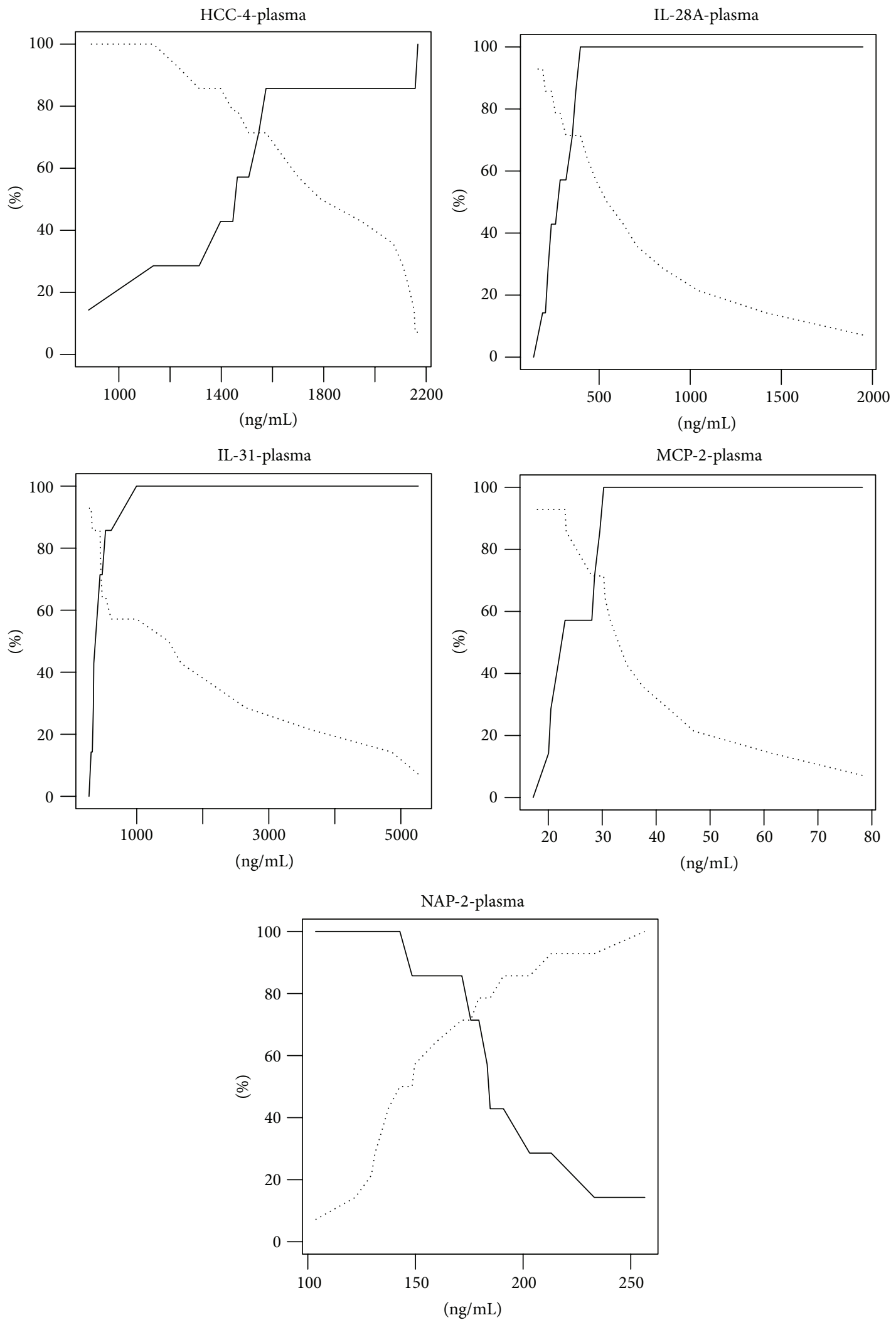

— Sensitivity Specificity

FIGURE 2: Sensitivity and specificity of markers in plasma: HCC-4, IL-28A, IL-31, MCP-2, and NAP-2 (CXCL7). 
TABLE 4: Diagnostic values of chemokines in plasma.

\begin{tabular}{lccccccccc}
\hline & $\begin{array}{c}\text { Threshold } \\
\text { value } \\
(\mathrm{pg} / \mathrm{mL})\end{array}$ & Sensitivity & 95\% CI for sensitivity & Specificity & 95\% CI for specificity & AUC & 95\% CI for AUC St. error & $P$ value \\
\hline HCC-4 & $<1574.65$ & 0.8571 & $0.4868-0.9743$ & 0.7142 & $0.4535-0.8827$ & 0.73 & $0.51-1$ & 0.13 & 0.0412 \\
IL-31 & $<443.6$ & 0.7142 & $0.3589-0.9177$ & 0.8571 & $0.6005-0.9599$ & 0.79 & $0.63-1$ & 0.1 & 0.0018 \\
IL-28A & $<397.33$ & 1 & $0.6456-1$ & 0.7142 & $0.4535-0.8827$ & 0.79 & $0.63-1$ & 0.1 & 0.0017 \\
MCP-2 & $<30.28$ & 1 & $0.6456-1$ & 0.7142 & $0.4535-0.8827$ & 0.84 & $0.69-1$ & 0.09 & 0.0001 \\
CXCL7 & $>171.56$ & 0.8571 & $0.4868-0.9743$ & 0.7142 & $0.4535-0.8827$ & 0.79 & $0.63-1$ & 0.1 & 0.0015 \\
\hline
\end{tabular}

TABLE 5: Diagnostic values of chemokines in amniotic fluid.

\begin{tabular}{lccccccccc}
\hline & $\begin{array}{c}\text { Threshold } \\
\text { value } \\
(\mathrm{pg} / \mathrm{mL})\end{array}$ & Sensitivity & 95\% CI for sensitivity & Specificity & 95\% CI for specificity & AUC & 95\% CI for AUC Std. error $P$ value \\
\hline IP-10 & $>1152.5$ & 0.8571 & $0.4868-0.9743$ & 0.7857 & $0.5241-0.9242$ & 0.8673 & $0.729-1$ & 0.08 & $<0.0001$ \\
MPIF-1 & $>189.62$ & 1 & $0.6456-1$ & 0.5 & $0.2679-0.7320$ & 0.7857 & $0.6075-1$ & 0.1 & 0.0041 \\
CXCL7 & $>479.81$ & 0.8571 & $0.4868-0.9743$ & 0.7857 & $0.5241-0.9242$ & 0.8469 & $0.7034-1$ & 0.08 & $<0.0001$ \\
6Ckine & $<5415.84$ & 0.8571 & $0.4868-0.9743$ & 0.7857 & $0.5241-0.9242$ & 0.7857 & $0.5666-1$ & 0.13 & 0.0159 \\
I-TAC & $<34.21$ & 0.8333 & $0.4364-0.9699$ & 0.9166 & $0.6461-0.9851$ & 0.875 & $0.7198-1$ & 0.09 & $<0.0001$ \\
MCP-3 & $<24.49$ & 1 & $0.5101-1$ & 0.833 & $0.5519-0.9530$ & 0.875 & $0.7222-1$ & 0.09 & $<0.0001$ \\
MIF & $<1483.82$ & 0.8571 & $0.4868-0.9743$ & 0.9166 & $0.6461-0.9851$ & 0.8809 & $0.7385-1$ & 0.08 & $<0.0001$ \\
\hline
\end{tabular}

has shown elevated level of IP-10 in amniotic fluid, whose production is also related to high level of IFN- $\gamma$ [30]. In order to clarify the exact role of these chemokines in Down syndrome pregnancies, additional factors that correlate with the above-mentioned proteins should be measured, which is planned to be tested in our laboratory in the near future.

MCP-2 (CCL8), MCP-3 (CCL7), MPIF-1 (CCL23) and 6 Ckine (CCL21) also belongs to the same family as HCC4 (CCL16) [34]. We have found reduced levels of MCP-2 in plasma. The concentration of MCP-3 was decreased in the amniotic fluid whereas concentrations of MPIF-1 and 6Ckine were increased in women with fetal Down syndrome compared to the control group.

IL-31 plays an important role in fundamental physiological processes such as growth of neurons, myocardium, immune system, reproductive system, respiratory system, and bone metabolism (experiments showed increased expression of genes encoding IL-31 mRNA in cells of: skin, brain, trachea, lung, placenta, ovary, testis, and skeletal muscle) [35], which are largely affected by fetus with trisomy of chromosome 21 during pregnancy. In our study, detected levels of IL-31 in the plasma of women with fetal Down syndrome were lower when compared to women with a healthy fetus. This could indirectly confirm the role of this protein in properly running processes of development of individual systems that are disrupted in people with Down syndrome. Bromage et al. found reduced levels of IL-6 in maternal plasma of fetal Down's syndrome [14]. IL-31 belongs to the same subgroup as interleukin IL- 6 and both act mainly through the same receptors.

It has been proven that fetal liver cells have an increased expression of gene associated with CXCL7 (NAP-2) in the innate immunity. This protein can be assigned to the central role of the liver in fetus in the process of hematopoiesis. It is believed that CXCL7 is associated with the production of active hormones by trophoblast cells and placenta during uncomplicated pregnancy [36]. Taking into account the plasma and amniotic fluid increase of CXCL7 in our study, it can be hypothesized that the liver of the fetus with trisomy of chromosome 21 produces increased amounts of this protein which in turn causes deregulation of trophoblasts hormones.

From our study, we excluded patients with symptoms of inflammation, which gives us a possibility to suspect that fluctuations of the chemokines concentration may be the result of fetal chromosomal aberration. The limitation of the study is lack of white blood count results and amniotic fluid culture which are not routinely performed before each amniocentesis in asymptomatic women.

In this publication, we showed that selected chemokines could be potential biomarkers of Down syndrome pregnancies and might play a role in the pathology of trisomy of chromosome 21 . In the international literature, there still exists no relevant research focused on the role of chemokines in the pathogenesis of Down syndrome. Therefore, it is difficult to definitely conclude on the variations in the levels of inflammatory factors. However, due to the complexity of the pathomechanism responsible for Down syndrome, further functional experiments should be performed.

\section{Conflict of Interests}

The authors declare that there is no conflict of interests regarding the publication of this paper. 


\section{Acknowledgment}

The authors are grateful to Joanna Goscik for her professional help in statistical analysis.

\section{References}

[1] S. L. Sherman, E. G. Allen, L. H. Bean, and S. B. Freeman, "Epidemiology of Down syndrome," Mental Retardation and Developmental Disabilities Research Reviews, vol. 13, pp. 221-227, 2007.

[2] S. Ghosh, E. Feingold, and S. K. Dey, "Etiology of down syndrome: Evidence for consistent association among altered meiotic recombination, nondisjunction, and maternal age across populations," American Journal of Medical Genetics A, vol. 149, no. 7, pp. 1415-1420, 2009.

[3] P. A. Benn, J. Ying, T. Beazoglou, and J. F. Egan, "Estimates for the sensitivity and false-positive rates for second trimester serum screening for Down syndrome and trisomy 18 with adjustment for cross-identification and double-positive results," Prenatal Diagnosis, vol. 21, pp. 46-51, 2001.

[4] P. Laudanski, A. Lemancewicz, P. Kuc et al., "Chemokines profiling of patients with preterm birth," Mediators of Inflammation, vol. 2014, Article ID 185758, 7 pages, 2014.

[5] P. Laudanski, A. Lemancewicz, P. Pierzynski, M. Akerlund, and T. Laudanski, "Decreased serum level of macrophage inflammatory chemokine-3 $\beta /$ CCL19 in preterm labor and delivery," European Journal of Obstetrics Gynecology and Reproductive Biology, vol. 124, no. 1, pp. 23-26, 2006.

[6] P. Laudanski, G. Raba, P. Kuc, A. Lemancewicz, R. Kisielewski, and T. Laudanski, "Assessment of the selected biochemical markers in predicting preterm labour," Journal of MaternalFetal and Neonatal Medicine, vol. 25, no. 12, pp. 2696-2699, 2012.

[7] M. Kuzmicki, B. Telejko, A. Zonenberg et al., "Circulating Pro- and anti-inflammatory cytokines in polish women with gestational diabetes," Hormone and Metabolic Research, vol. 40, no. 8, pp. 556-560, 2008.

[8] S. Guven, S. C. Karahan, O. Kandemir, U. Ucar, A. O. Cora, and H. Bozkaya, "Occult inflammation and/or ischemia may be responsible for the false positivity of biochemical Down syndrome screening test," Journal of Perinatal Medicine, vol. 38, no. 4, pp. 367-371, 2010.

[9] P. G. Nelson, T. Kuddo, E. Y. Song et al., "Selected neurotrophins, neuropeptides, and cytokines: developmental trajectory and concentrations in neonatal blood of children with autism or Down syndrome," International Journal of Developmental Neuroscience, vol. 24, no. 1, pp. 73-80, 2006.

[10] E. M. Wallace, B. Marjono, D. A. Brown et al., "Maternal serum and amniotic fluid levels of macrophage inhibitory cytokine 1 in Down syndrome and chromosomally normal pregnancies," Prenatal Diagnosis, vol. 24, no. 3, pp. 224-226, 2004.

[11] A. L. Tranquilli, V. Bezzeccheri, C. Scagnoli, L. Mazzanti, and G. G. Garzetti, "Amniotic levels of vascular endothelial growth factor and nitric oxide at the second trimester in Down's syndrome," Journal of Maternal-Fetal and Neonatal Medicine, vol. 13, no. 1, pp. 28-31, 2003.

[12] M.-T. Gervasi, R. Romero, G. Bracalente et al., "Midtrimester amniotic fluid concentrations of interleukin-6 and interferongamma-inducible protein-10: evidence for heterogeneity of intra-amniotic inflammation and associations with spontaneous early (<32 weeks) and late ( $>32$ weeks) preterm delivery," Journal of Perinatal Medicine, vol. 40, no. 4, pp. 329-343, 2012.
[13] P. Kuc, P. Laudański, O. Kowalczuk, L. Chyczewski, and T. Laudański, "Expression of selected genes in preterm premature rupture of fetal membranes," Acta Obstetricia et Gynecologica Scandinavica, vol. 91, no. 8, pp. 936-943, 2012.

[14] S. J. Bromage, A. K. Lang, I. Atkinson, and R. F. Searle, "Abnormal TGF $\beta$ levels in the amniotic fluid of Down syndrome pregnancies," The American Journal of Reproductive Immunology, vol. 44, no. 4, pp. 205-210, 2000.

[15] F. Vesce, C. Scapoli, G. Giovannini et al., "Cytokine imbalance in pregnancies with fetal chromosomal abnormalities," Human Reproduction, vol. 17, no. 3, pp. 803-808, 2002.

[16] V. Costa, L. Sommese, A. Casamassimi et al., "Impairment of circulating endothelial progenitors in Down syndrome," BMC Medical Genomics, vol. 3, article 40, 2010.

[17] J. M. Chambers, A. Freeny, and R. M. Heiberger, "Analysis of variance; designed experiments," in Statistical Models in S, Wadsworth \& Brooks/Cole, Pacific Grove, Calif, USA, 1992.

[18] F. Wilcoxon, "Probability tables for individual comparisons by ranking methods," Biometrics. Journal of the Biometric Society, vol. 3, pp. 119-122, 1947.

[19] S. S. Shapiro and R. S. Francia, "An Approximate Analysis of Variance Test for Normality," 2012.

[20] H. Levene, "Robust tests for equality of variances," in Contributions to Probability and Statistics: Essays in Honor of Harold Hotelling, vol. 1, pp. 278-292, Stanford University Press, 1960.

[21] W. J. Youden, "Index for rating diagnostic tests," Cancer, vol. 3, no. 1, pp. 32-35, 1950.

[22] E. B. Wilson, "Probable Inference, The Law of Succession, and Statistical Inference," 2012.

[23] E. R. DeLong, D. M. DeLong, and D. L. Clarke-Pearson, "Comparing the areas under two or more correlated receiver operating characteristic curves: a nonparametric approach," Biometrics, vol. 44, no. 3, pp. 837-845, 1988.

[24] X. Robin, N. Turck, A. Hainard et al., "pROC: an open-source package for R and $\mathrm{S}+$ to analyze and compare ROC curves," BMC Bioinformatics, vol. 12, article 77, 2011.

[25] GBIF, "Resources-tools and information to support the GBIF community," 2014.

[26] P. Sheppard, W. Kindsvogel, W. Xu et al., "IL-28, IL-29 and their class II cytokine receptor IL-28R," Nature Immunology, vol. 4, no. 1, pp. 63-68, 2003.

[27] L. Paulesu, V. Bocci, A. King, and Y. M. Loke, "Immunocytochemical localization of interferons in human trophoblast populations," Journal of Biological Regulators and Homeostatic Agents, vol. 5, no. 3, pp. 81-85, 1991.

[28] H. Nomiyama, S. Fukuda, M. Iio, S. Tanase, R. Miura, and O. Yoshie, "Organization of the chemokine gene cluster on human chromosome 17q11.2 containing the genes for CC chemokine MPIF-1, HCC-2, HCC-1, LEC, and RANTES," Journal of Interferon and Cytokine Research, vol. 19, no. 3, pp. 227-234, 1999.

[29] A. D. Luster, J. C. Unkeless, and J. V. Ravetch, " $\gamma$-interferon transcriptionally regulates an early-response gene containing homology to platelet proteins," Nature, vol. 315, no. 6021, pp. 672-676, 1985.

[30] M. R. Sandhya Rani, G. R. Foster, S. Leung, D. Leaman, G. R. Stark, and R. M. Ransohoff, "Characterization of $\beta$-R1, a gene that is selectively induced by interferon $\beta$ (IFN- $\beta$ ) compared with IFN- $\alpha$," Journal of Biological Chemistry, vol. 271, no. 37, pp. 22878-22884, 1996.

[31] K. Mäkikallio, T. Kaukola, J. Tuimala, S. F. Kingsmore, M. Hallman, and M. Ojaniemi, "Umbilical artery chemokine 
CCL16 is associated with preterm preeclampsia and fetal growth restriction," Cytokine, vol. 60, no. 2, pp. 377-384, 2012.

[32] R. L. Jones, N. J. Hannan, T. J. Kaitu'u, J. Zhang, and L. A. Salamonsen, "Identification of chemokines important for leukocyte recruitment to the human endometrium at the times of embryo implantation and menstruation," The Journal of Clinical Endocrinology \& Metabolism, vol. 89, no. 12, pp. 61556167, 2004.

[33] S. K. Gantsev, K. Umezawa, D. V. Islamgulov et al., “The role of inflammatory chemokines in lymphoid neoorganogenesis in breast cancer," Biomedicine and Pharmacotherapy, vol. 67, no. 5, pp. 363-366, 2013.

[34] M. R. Faria, M. S. Hoshida, E. A. V. Ferro, F. Ietta, L. Paulesu, and E. Bevilacqua, "Spatiotemporal patterns of macrophage migration inhibitory factor (Mif) expression in the mouse placenta," Reproductive Biology and Endocrinology, vol. 8, article 95, 2010.

[35] Q. Zhang, P. Putheti, Q. Zhou, Q. Liu, and W. Gao, "Structures and biological functions of IL-31 and IL-31 receptors," Cytokine and Growth Factor Reviews, vol. 19, no. 5-6, pp. 347-356, 2008.

[36] J. L. A. Pennings, M. P. H. Koster, W. Rodenburg, P. C. J. I. Schielen, and A. de Vries, "Discovery of novel serum biomarkers for prenatal down syndrome screening by integrative data mining," PLoS ONE, vol. 4, no. 11, Article ID e8010, 2009. 


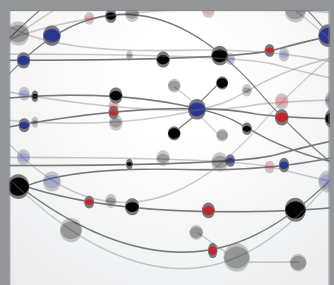

The Scientific World Journal
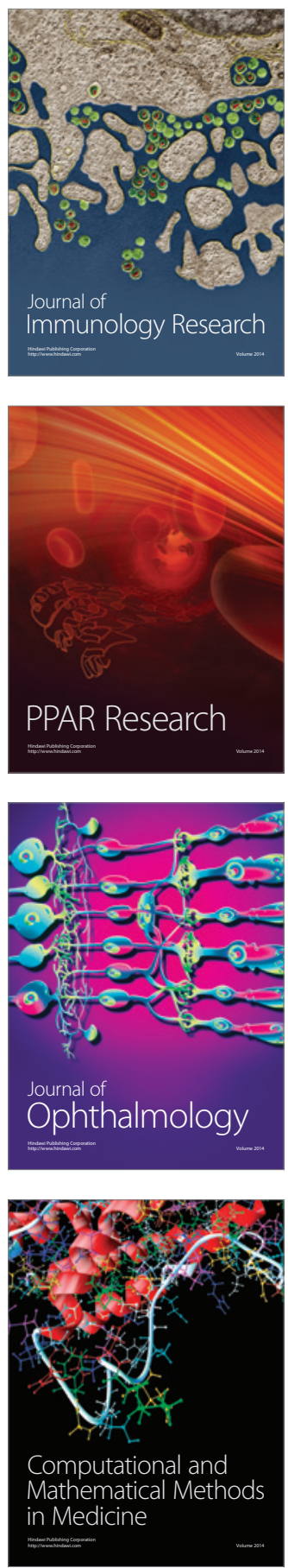

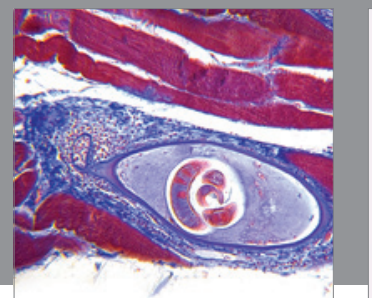

Gastroenterology

Research and Practice
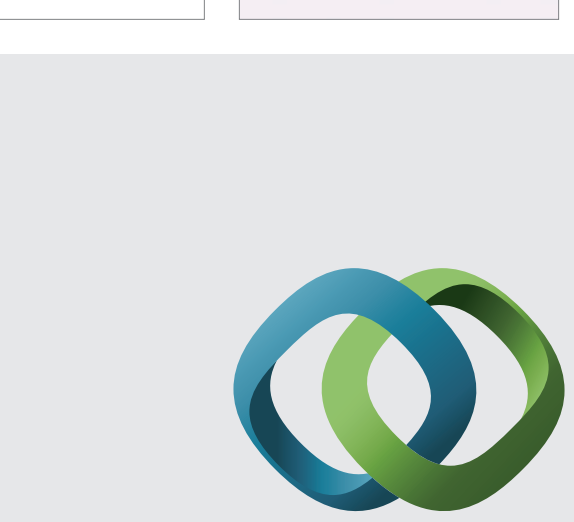

\section{Hindawi}

Submit your manuscripts at

http://www.hindawi.com
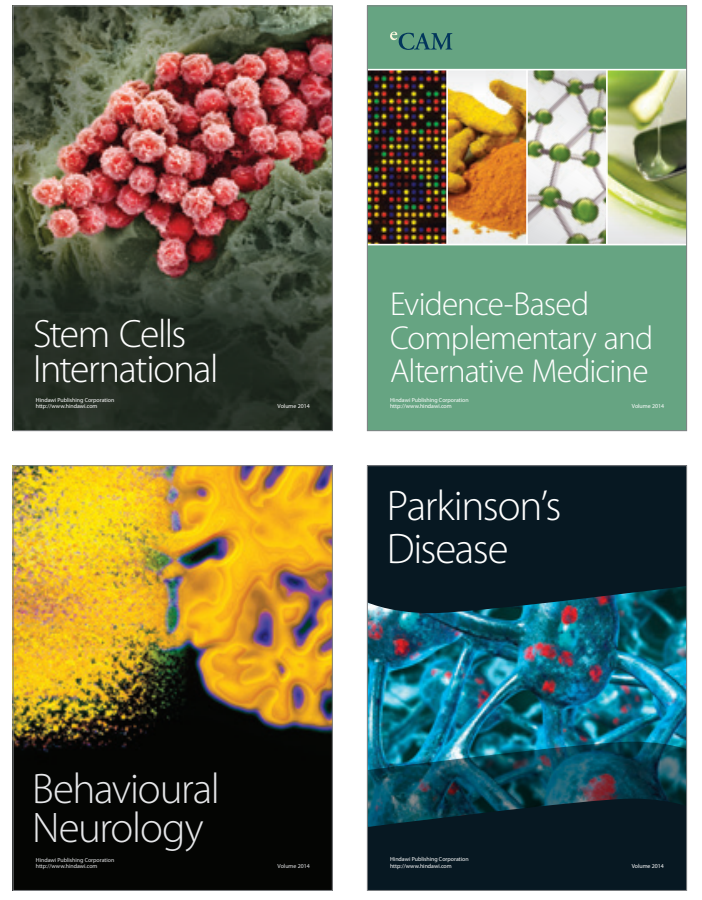
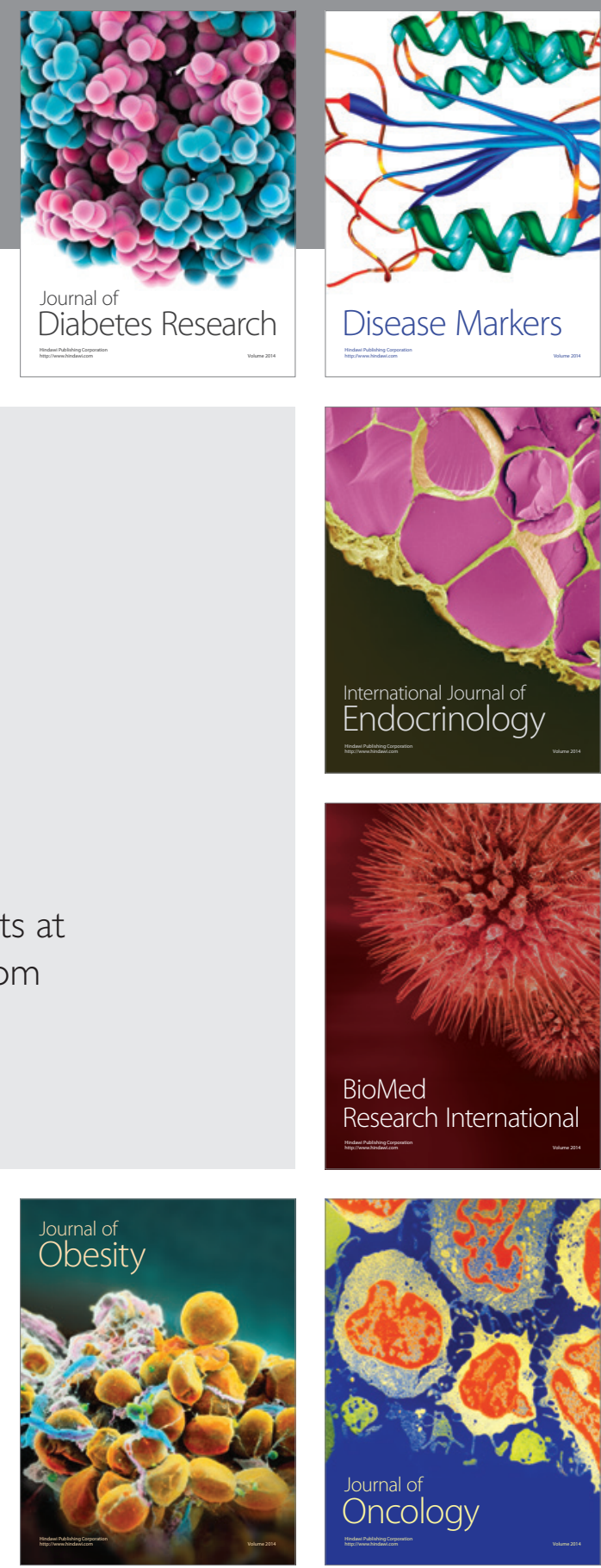

Disease Markers
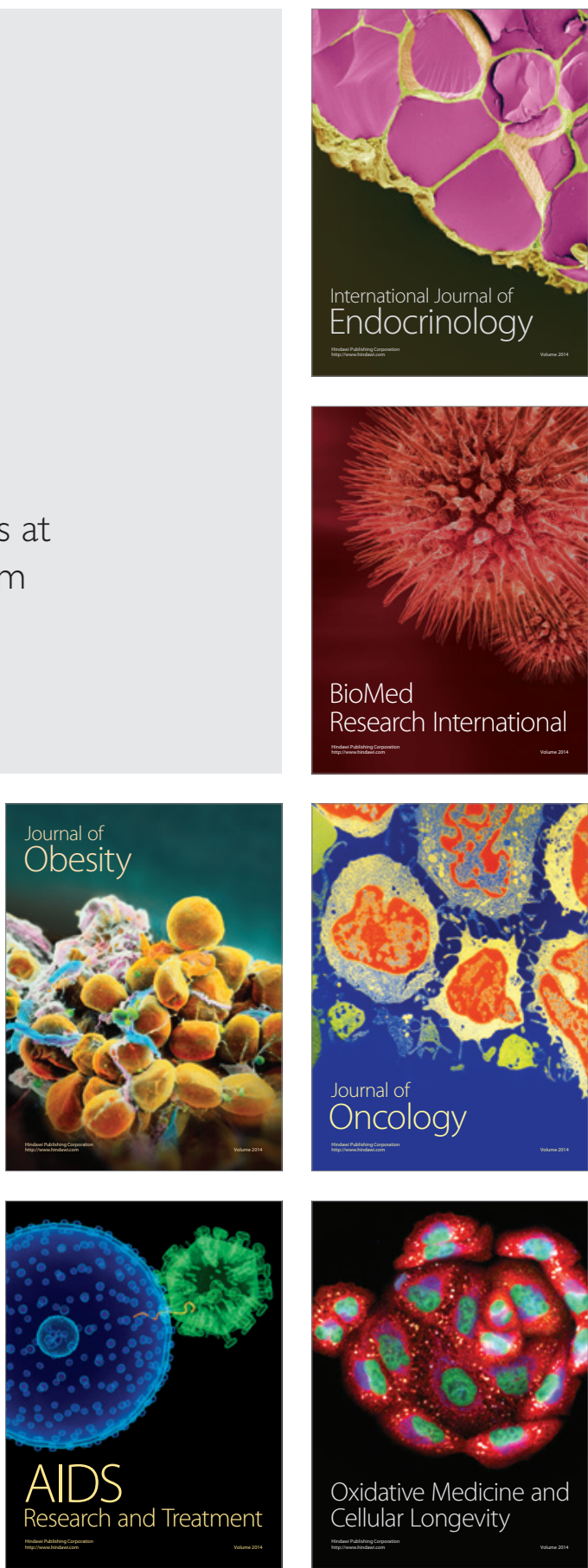